\title{
Design and Analysis of a Water Pumping System with Photovoltaic Source and Switched Reluctance Motor
}

\author{
Z. OMAÇ
}

\begin{abstract}
Solar energy is a clean energy and it is increasingly being used all over the world. In this study, a centrifugal water pump system driven by switched reluctance motor (SRM) has been designed with powered by a photovoltaic (PV) energy source. The voltage of the PV source has been increased by using a boost converter. The mathematical model of the system has been composed in the Matlab/Simulink and simulation results have been obtained. Proportional-integral-derivative (PID) controller has been used to control output voltage of the boost converter at $50 \mathrm{kHz}$ switching frequency. The boost converter is controlled by an eight-bit PIC16F877A microcontroller. The electrical energy obtained by PV panels has been stored in batteries. Battery charge testers have been used to control the battery charge level. The speed and current control of SRM has been done by using DS1103 Ace kit. The values of phases currents have been measured by using hall sensors and transferred to the digital signal processor (DSP) by analog to digital converter inputs. The accuracy of simulation results has been proved by experimental results.
\end{abstract}

Index Terms - Solar Energy, Switched Reluctance Motor, Boost Converter, Photovoltaic energy (PV), Digital Signal Processor (DSP).

\section{INTRODUCTION}

A S A RESULT of increasing usage of the solar energy and developments in technology, photovoltaic (PV) pumping systems are put into operation [1]. PV pumping systems generally have a PV unit, a motor and a pump. Induction motors and direct current (DC) motors are mostly used in these systems [2].

Induction motors have a simple structure and they are also cheap. To run induction motors with minimum harmonics, they need complex alternating current (AC) power inverters. DC motors are very complicated and expensive motors and they have commutation segments and brushes. Therefore, DC motors have bigger maintenance problems than SRM. DC

ZEKİ OMAÇ, is with Department of Electrical and Elecronics Engineering Munzur University, Tunceli, Turkey,(e-mail: zomac@ munzur.edu.tr).

iD https://orcid.org/0000-0002-9339-8243 motors have not only problem of limited size and speed but also arc problem. Switched reluctance motors (SRM) have advantages such as higher torque compared with the inertia, robust and reliable structure which are make them simple and cheap. Moreover, it has a simple power electronic converter and the ability to run at high efficiency and high speed [3]-[6].

This study displays the design of a water pumping system based on photovoltaic energy and switched reluctance motor. For increasing the voltage of PV panels, DC - DC boost converter has been used in the present study. All the system is modeled and analyzed by using MATLAB/Simulink software. Simulation results and experimental results are compared in this work to see the accuracy of the model developed. Additionally, it is targeted to contribute to the use of solar energy in countries that use solar energy widely.

\section{DC-DC CONVERTERS}

Because of the high stability and efficiency of DC - DC switching converter, it has been used in the fields of mobile communications, industrial applications, home appliances and so on. The analyses and design of the switch converter have already become the key points of the researches. There are two basic operation modes, which are classified as continuous conduction mode (CCM) and discontinuous conduction mode, on DC - DC converters [7].

Several studies have examined the direct current (DC) power distribution technology as a promising candidate for future power systems. However, the efficiency and reliability of DC power converters already used have not been comparable with those of AC transformers yet [4].

The most popular DC - DC converters of both non - isolated and isolated converters are classified as buck (step - down), boost (step - up) and buck - boost (step down - up) converters [7]. Buck converters decrease the input voltage where boost converters increase it. Buck - boost converters change the input voltage to a negative value. Since a boost converter is used in this study, it will be under our focus.

When a small change is made on a buck converter, a boost converter can be achieved. The boost converter is shown in Fig. 1. It is also known as "the step - up DC - DC converter" due to its voltage boosting function. 


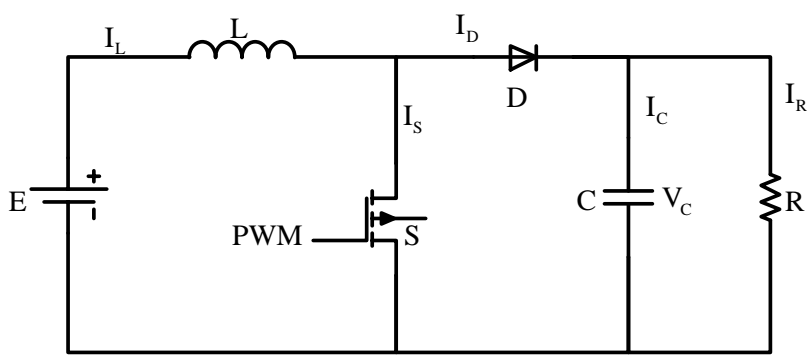

Fig. 1. The DC - DC boost converter circuit.

When the switch $\mathrm{S}$ is on, the inductor current is

$$
\begin{aligned}
\frac{d i_{L}}{d t} & =\frac{E}{L} \\
\frac{d V_{C}}{d t} & =-\frac{V_{C}}{R \cdot C}
\end{aligned}
$$

Where $E$ is DC input voltage, $V_{C}$ is the DC output voltage, $L$ is the inductance of inductor, $i_{L}$ is inductor current, $R$ is the load resistance, $\mathrm{C}$ is the capacitance and $i_{c}$ is the capacitance current for DC-DC boost converter. When the switch S is off, the equation becomes

$$
\begin{aligned}
& \frac{d i_{L}}{d t}=\frac{E-V_{C}}{L} \\
& i_{C}=i_{L}-\frac{V_{C}}{R}
\end{aligned}
$$

The type of converter to be used is determined depending on the load. The power electronic components such as MOSFET, IGBT are strongly influenced by the component temperature in these converters [6]. In addition, manufacturer's tolerances in cell characteristics, environmental stresses and shadow problems may lead to mismatches of each PV module caused significant losses. DC - DC converters in series are used to solve these problems [7]. Switching loss is one of the prominent problems of converters. Because of switching losses and electromagnetic interference (EMI), switching frequency in hard - switched DC - DC converters cannot be significantly raised. To increase the efficiency and average power of DC - DC converter, soft switching techniques, which can minimize the switching losses of the converters, should be applied. It is generally implemented by adding an active or passive snubber circuit [8]-[12].

\section{MATHEMATICAL MODEL OF SRM}

Variable Reluctance Motors (VRM) have this name since they have variable reluctance due to the change in the air gap with respect to the rotor position. Although the theory of variable reluctance motors was known for a long time, they have been begun to be used for adjustable speed applications since 1980s.

The term "switched reluctance motor" (SRM) is used to refer to both variable reluctance motor and its driver circuit together. SRM has several advantages such as the simple power electronic converter requirement, fault tolerance, high efficiency and capability for very high-speed operations. In addition, due to their simple and robust structures, easy manufacturing and the possibility of exploiting power converts with a reduced number of switches, SRM can be a viable alternative to universal motors and AC machines. Furthermore, due to motor structure and converter, switched reluctance motor (SRM) drive has high application potential for electric vehicles (EV) within a wide speed range. Besides, asymmetric bridge converter is usually used in SRM among all SRM converters. In the literature, the features of the SRM are discussed widely and their advantages and disadvantages are investigated in three sections as motor, driver and control [13]- [15].

Linear working conditions that neither inductance changes with current, nor magnetic saturation occurs are assumed for mathematical model of SRM. Since the mutual inductances between the phases are too small, they are ignored. Fig. 2 shows the cross-sectional illustration of the SRM used to actuate the centrifugal pump.

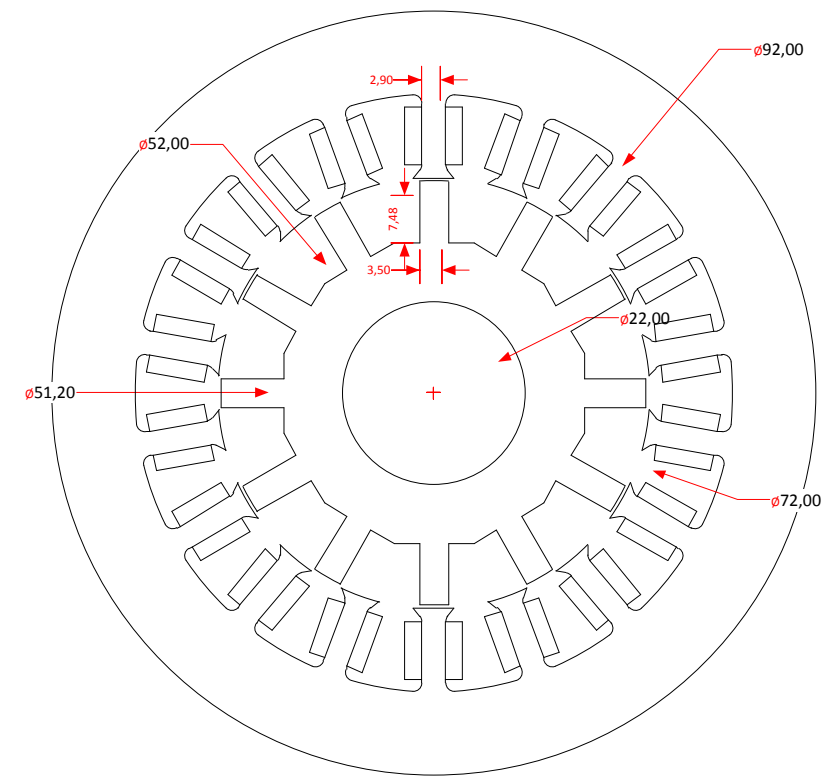

Fig. 2. Cross section of a switched reluctance motor driven water pumping system.

The phase winding voltage equation of SRM can be expressed as

$$
V=R i+\frac{d \psi(\theta, i)}{d t}
$$

Where $V$ is the phase voltage, $i$ is the phase current, $R$ is the phase resistance and $\psi$ is the phase flux linkage. Flux linkage is a function of the rotor position and phase current. The phase winding voltage equation of SRM can be rewritten as

$$
V=R i+\frac{\partial \psi}{\partial i} \frac{d i}{d t}+\frac{\partial \psi}{\partial \theta} \frac{d \theta}{d t}
$$

and 


$$
\omega=\frac{d \theta}{d t}
$$

Where $\theta$ is the rotor position, and $\omega$ is the angular speed of rotor. The relationship between the inductance $(L)$ and the rotor position and phase current are given by Eq. (8);

$$
L=\frac{\partial \psi}{\partial i}
$$

The product of the self - inductance and the instantaneous phase current give the flux linkage in an active phase as

$$
\psi=i . L
$$

Rearranging Equation (6) gives

$$
V=R i+L \frac{d i}{d t}+i \frac{d L}{d \theta} \omega
$$

The third term of the right side of Equation (10) is the induced back electromotive force (EMF):

$$
E=i \frac{d L}{d \theta} \omega
$$

The inductance $L$ varies between maximum and minimum values. Maximum $L_{\max }$ and minimum inductance $L_{\min }$ take place when the rotor and stator poles axis are aligned and rotor and stator poles axis is unaligned, respectively.

The electromechanical torque $(T)$ produced by the SRM is given by Equation (12),

$$
T=\frac{1}{2} i^{2} \frac{d L}{d \theta}
$$

We can rewrite the whole torque equation (13) for the SRM.

$$
T_{e}\left(\theta, i_{a}, i_{b}, i_{c}\right)=T_{a}\left(\theta, i_{a}\right)+T_{b}\left(\theta, i_{b}\right)+T_{c}\left(\theta, i_{c}\right)
$$

The mechanical equation of an SRM can be defined as:

$$
T_{e}=J \frac{d \theta^{2}}{d t^{2}}+B \frac{d \theta}{d t}+T_{L}
$$

Where $T_{L}, J$, and $B$ are the load torque, inertia, and damping coefficient, respectively. Substitution into Equation (7) gives

$$
T_{e}=J \frac{d \omega}{d t}+B \omega+T_{L}
$$

Equations (10) and (15) have the state equation form as shown below.

$$
\begin{aligned}
& \frac{d i}{d t}=\frac{1}{L}\left[V-\left(R i+i \frac{d L}{d \theta} \omega\right)\right] \\
& \frac{d \omega}{d t}=\frac{1}{J}\left[T_{e}-\left(B \omega+T_{L}\right)\right] \\
& \frac{d \theta}{d t}=\omega
\end{aligned}
$$

The torque is not unaffected by the polarity of phase current. To minimize ripples and to produce a smoother torque, the current supplied by the converter must be a square wave.

In general, SRM drives can be designed as two different types as current - controlled and voltage - controlled. Each drive type has some advantages and disadvantages. Current controlled drives are particularly suitable at low speeds. Therefore, the torque can be controlled with minimum ripple level in the constant torque region. Voltage - controlled drive is suitable for high - speed operation, but it is difficult to provide constant current at high speeds due to high back EMF. A good controller is expected to be able to operate at four quadrants, having low torque ripples, rapid response and good stability while it can start the motor at zero speed [13].

\section{CONTROL OF SRM}

A good motor drive should have high efficiency and low cost. The construction of SRMs is simple and its manufacturing cost is low. The cost tends to increase as SR machines need auxiliary components, such as converters, rotor position sensors, current sensors, etc.

The triggering times of the switches of the drive circuit of an SRM depends on the position of the rotor. In order to control the current in the SRM phase windings, it is essential to know the rotor position. In SRM drives, rotor position information is essential for the stator phase commutation and advanced angle control. The rotor position is usually observed by position sensors.

Figure 3 consisting of the PV source, boost converter, SRM and centrifugal pump shows the block diagram of the overall system. Fig. 4 shows a converter configuration for a three phase SRM with two power switches per phase. The control unit generates gate signals regarding motor current, rotor position and motor operating mode (forward or reverse) for each switch.

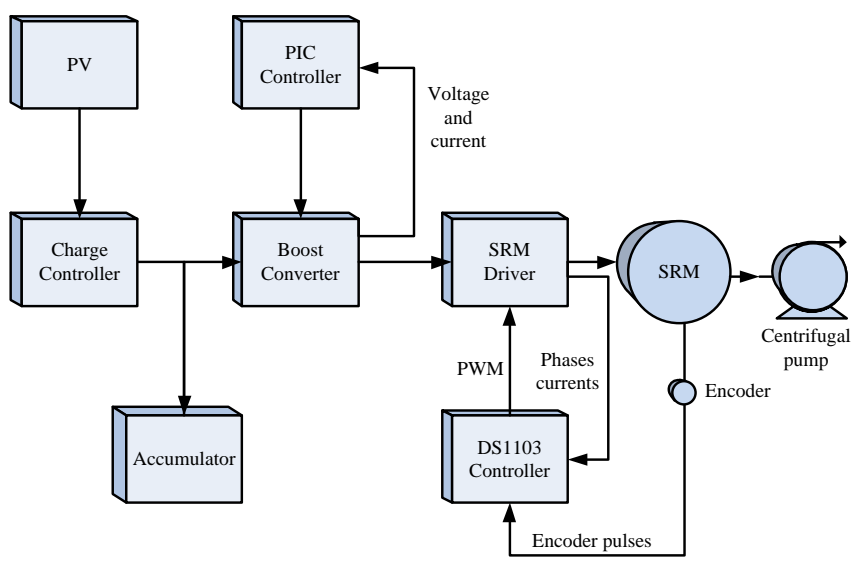

Fig. 3. The block diagram of the water pumping system with photovoltaic source and switched reluctance motor.

The average torque can be controlled by adjusting the current of the windings or by changing triggering angle. To minimize the variations in the torque, it is recommended to keep the triggering angle constant and to change the amplitude of the winding currents [14]. The average torque is the sum of 
simultaneous pulses of electromagnetic torque produced by all phases. The machine produces discrete pulses of torque, but it is possible to produce a constant torque by overlapping phase inductance graphics partially.

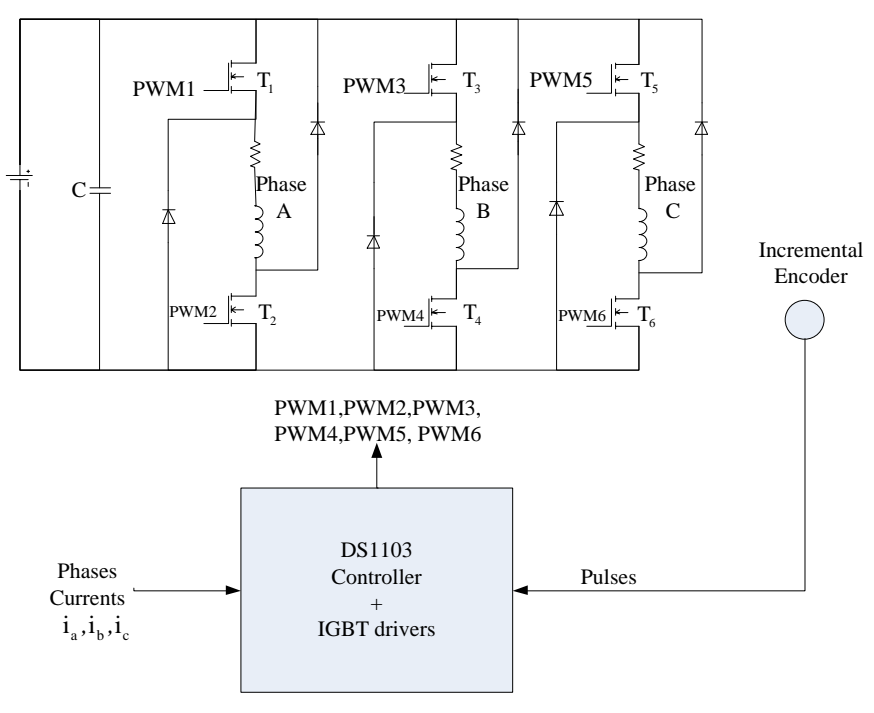

Fig. 4. Asymmetrical half-bridge converter and digital signal processor for SRM.

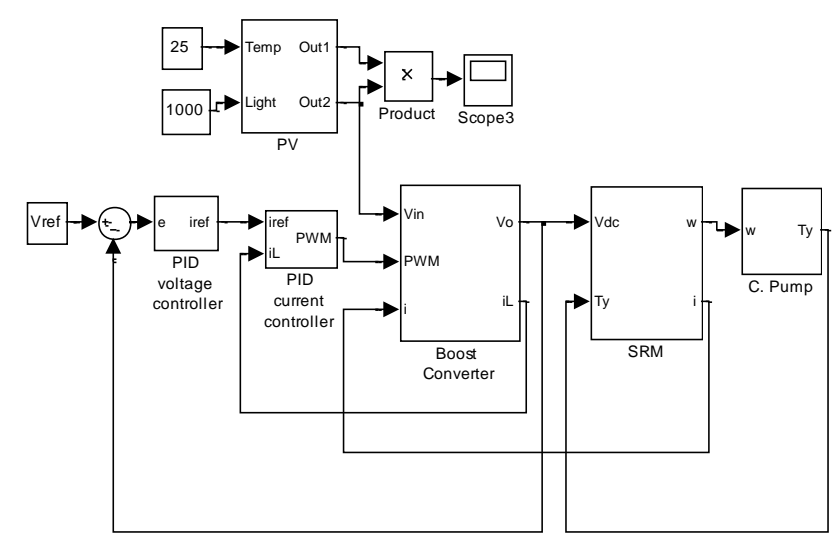

Fig. 5. Matlab/Simulink model of water pumping system with photovoltaic source and switched reluctance motor.

For positive torque generating, the pulses of phase current must coincide with a period of increasing inductance. Because of the presence of the inductor, the current cannot suddenly change. That's why forward voltage is applied at the beginning of the inductance curve with the positive slope to reach the maximum value of current on time. SRMs need a good commutation to decrease the phase current to zero before negative slope region of the inductance curve. Since the back EMF is lower than the line voltage under base speed, the torque is controlled with pulse width modulation (PWM). PWM current control is not possible above base speed because of high back EMF. The control of SRM speed is performed only by changing the triggering angles in the constant power region [13]. The control parameters above base speed are only the triggering angles. The linear model of SRM is simulated with Matlab/Simulink software. Block diagram of simulink model of water pumping system with photovoltaic source and SRM is presented in Fig. 5.

The hardware of the experiment contains motor drive circuit of IGBTs, DSP and the sensors that measure current, voltage and speed. Processing of speed and current values and generation of appropriate pulse width modulation (PWM) constitute the software part of experimental study.

DSPs are used widely in motion control. Control of switched reluctance motors with DSP has become the most developed technique. Because of its digital processing capacity, DSPs are used to control all types of electrical motors. DSPs have the necessary features and hardware optimizations to be used directly for control. Some of these features are the shorter execution time for instructions and ability to make multiplication and other instructions in one machine cycle. High performance DSPs are used in the applications which require very fast execution of the control algorithm. In recent years, more than one system can be controlled at the same time with the help of very fast DSPs [15]. There are DSPs having similar features produced by various firms. In this work DS1103 Ace kit produced by Dspace has been used.

\section{EXPERIMENTAL SETUP}

Fig. 6 is the photograph of the PV unit used in the experiment set. Fig. 7, 8 and 9 are the photographs of other units of the system. The system consists of PV panels, batteries, fuse box, regulator, boost converter driver circuit and the pump. The code file used to operate the DS1103 can be run after the blocks are prepared with Matlab/Simulink and compiled. The file is optimized by the compiler after Matlab/Simulink simulation for faster execution. In this work, the program is prepared with Matlab/Simulink to control the SRM is transferred to the DSP.

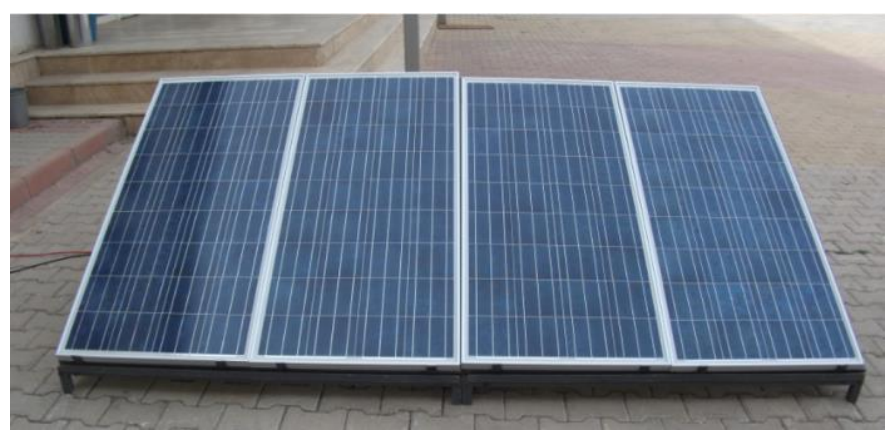

Fig. 6. PV array.

Pumps can be defined as machines that convert mechanical energy to hydraulic energy. There are various types of pumps classified into mainly two groups as volumetric and centrifugal. Various types of pumps and motors are ready for use in the PV pump market. The most commonly used type is the centrifugal pump [17]. 


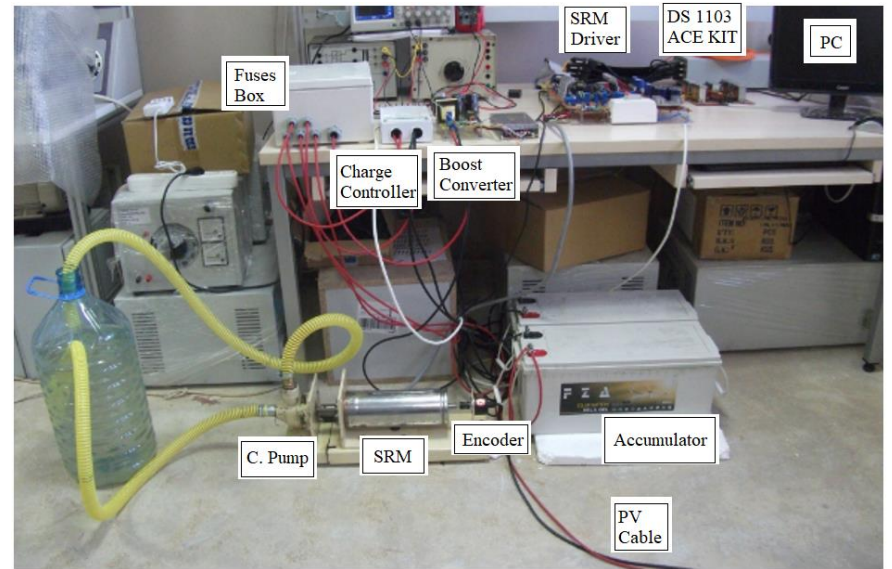

Fig. 7. Experiment set.

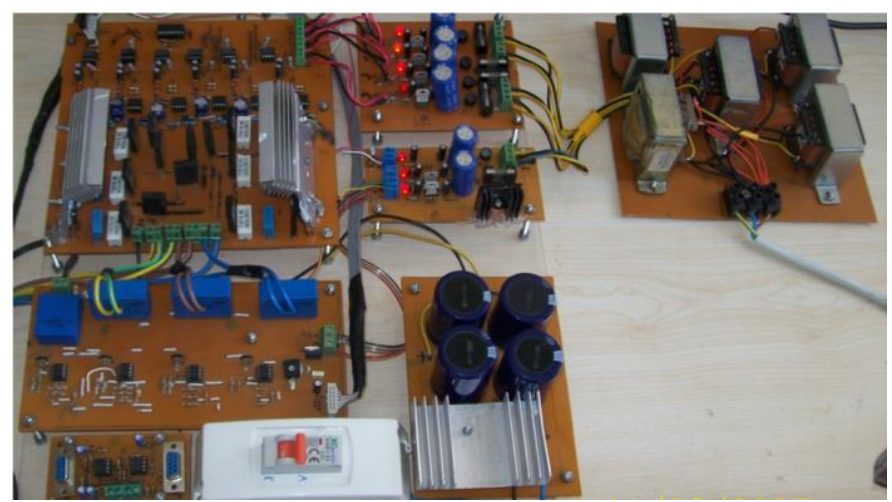

Fig. 8. The SRM driver.

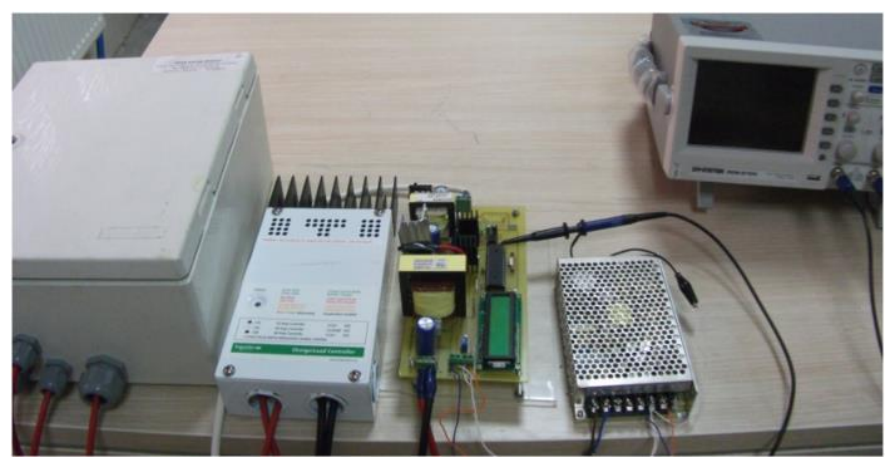

Fig. 9. The photo of DC-DC boost converter.

Centrifugal pumps are preferred in low - height suction applications, especially if they are directly interfaced with the solar panels. In addition, these pumps are suitable for pumping high volumes of water and they comparably have high efficiency [16].

\section{SIMULATION AND EXPERIMENTAL RESULTS}

Simulation parameters of SRM and boost converter are presented in Table I. The boost converter (Fig. 9) used to increase DC battery voltage (24 V) and SRM have been

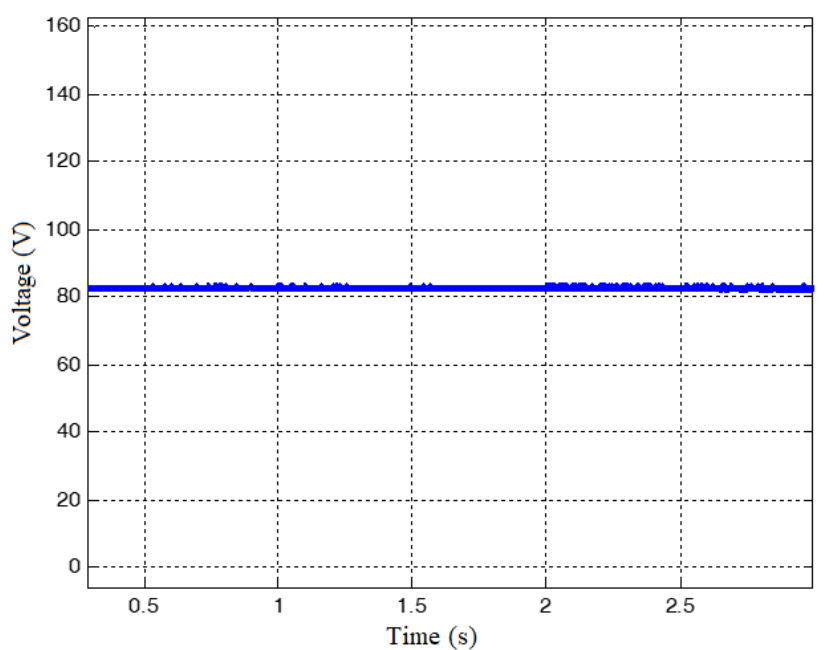

Fig. 10. Output voltage of the boost converter

TABLE I

SIMULATION PARAMETERS OF SRM AND BOOST CONVERTER

\begin{tabular}{ll}
\hline Parameters & Values \\
\hline Number of stator/rotor poles $\left(\mathrm{N}_{\mathrm{s}} / \mathrm{N}_{\mathrm{r}}\right)$ & $18 / 12$ \\
Rated power $\left(\mathrm{P}_{\mathrm{n}}\right)$ & $1.7 \mathrm{~kW}$ \\
Rated current $\left(\mathrm{I}_{\mathrm{n}}\right)$ & $6.5 \mathrm{~A}$ \\
Rated voltage $\left(\mathrm{V}_{\mathrm{n}}\right)$ & $300 \mathrm{~V}$ \\
A phase winding resistance $(\mathrm{R})$ & $2.6 \Omega$ \\
Friction coefficient $(\mathrm{B})$ & $0.00018 \mathrm{Nm} / \mathrm{rad} / \mathrm{s}$ \\
Moment of inertia $(\mathrm{J})$ & $0.000695 \mathrm{kgm}$ \\
Aligned position inductance $\left(\mathrm{L}_{\max }\right)$ & $7.29 \mathrm{mH}$ \\
Unaligned position inductance $\left(\mathrm{L}_{\min }\right)$ & $2.36 \mathrm{mH}$ \\
Battery voltage & $24 \mathrm{~V}$ \\
Boost converter inductance value $(\mathrm{L})$ & $200 \mu \mathrm{H}$ \\
Boost converter switching frequency & $50 \mathrm{kHz}$ \\
Boost converter capacitor value $(\mathrm{C})$ & $1000 \mu \mathrm{F}$ \\
SRM converter switching frequency & $15 \mathrm{kHz}$ \\
Proportionality coefficient $\left(\mathrm{K}_{\mathrm{p}}\right)$ & 30 \\
Integral coefficient $\left(\mathrm{K}_{\mathrm{i}}\right)$ & 0.5 \\
Derivative coefficient $\left(\mathrm{K}_{\mathrm{d}}\right)$ & 0.001 \\
\hline
\end{tabular}

designed and simulated in Matlab/Simulink [17]. Then, bias and measurement circuits have been designed and connected. After tests and adjustments, the system has become ready to operate.

Boost converter has been designed later. Firstly, its circuit board has been manufactured. After that, the tests and measurements are started. In our experiment, the switching frequency of the boost converter is $50 \mathrm{kHz}$ and the output voltage is regulated to the reference voltage of $80 \mathrm{~V}$ (Fig. 10). The switching frequency of the boost converter is observed by an oscilloscope. The four series - connected PV module that provide a rated output power of $600 \mathrm{~W}$ was used to supply motor. This PV module provides a rated output voltage of 80 $\mathrm{V}$. Thus, the power loss of transmission line is reduced for higher current values, by increasing the voltage.

The connections and adjustments between PV panels and batteries has been done and recharge regulator has been used to control the charge level of batteries. 


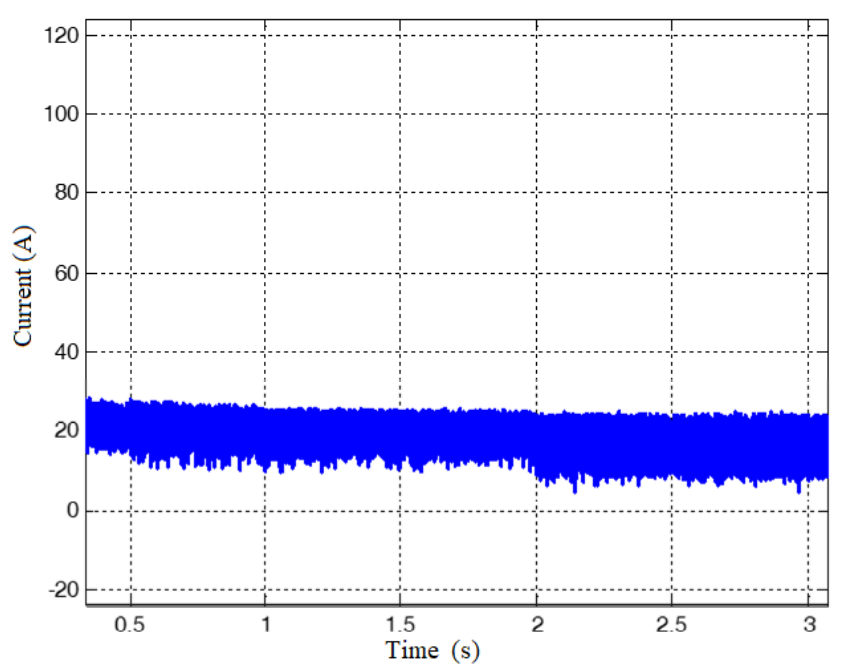

(a)

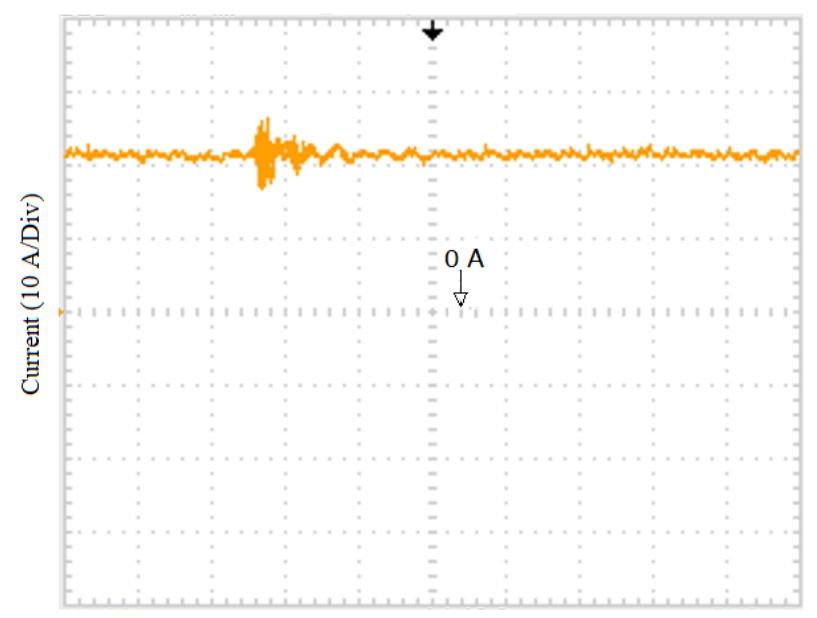

Time (10ms/Div)

(b)

Fig. 11. Inductor current of the boost converter. (a) The simulation result, (b) The experimental result.

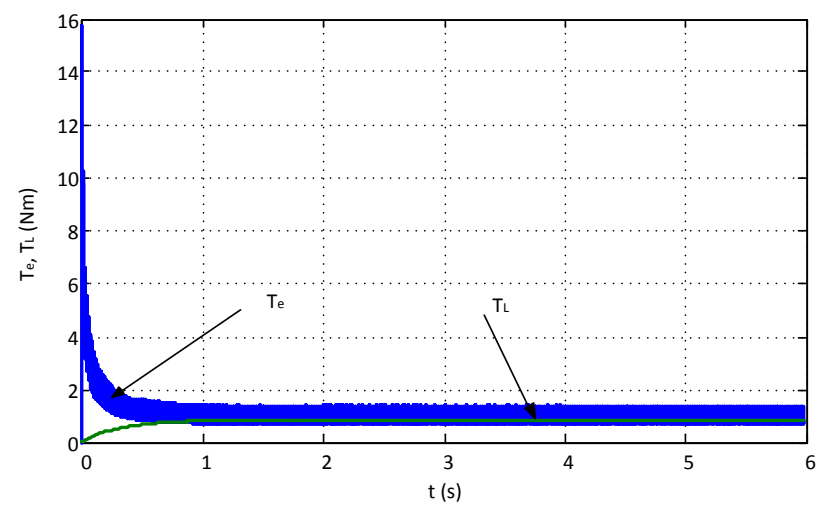

Fig.12. Simulation result of produced torque $\left(\mathrm{T}_{\mathrm{e}}\right)$ by SRM and load torque $\left(\mathrm{T}_{\mathrm{L}}\right)$

A fuse box has been added for safe operation. Then, the system has been tested and the battery supply currents have been measured.

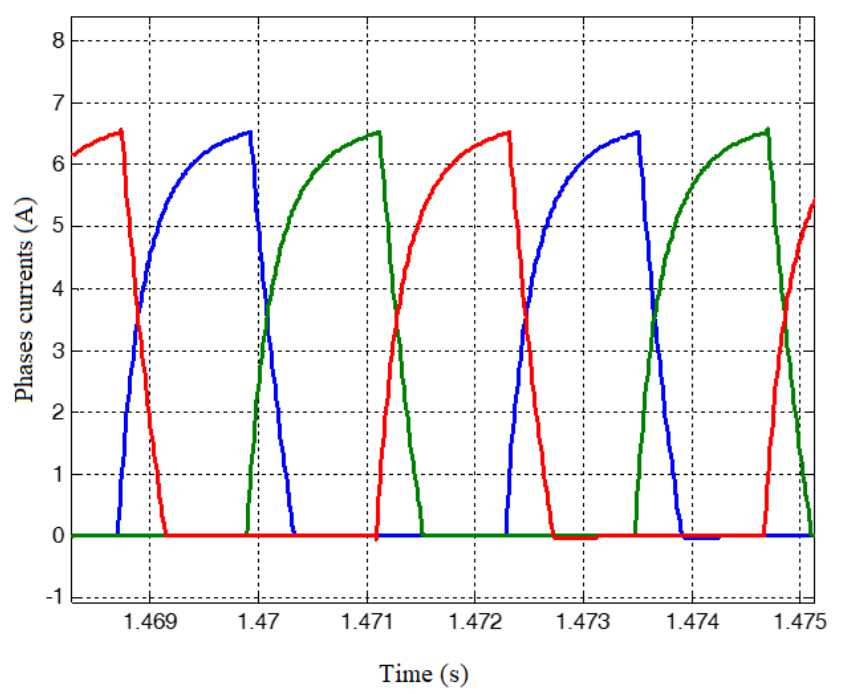

(a)

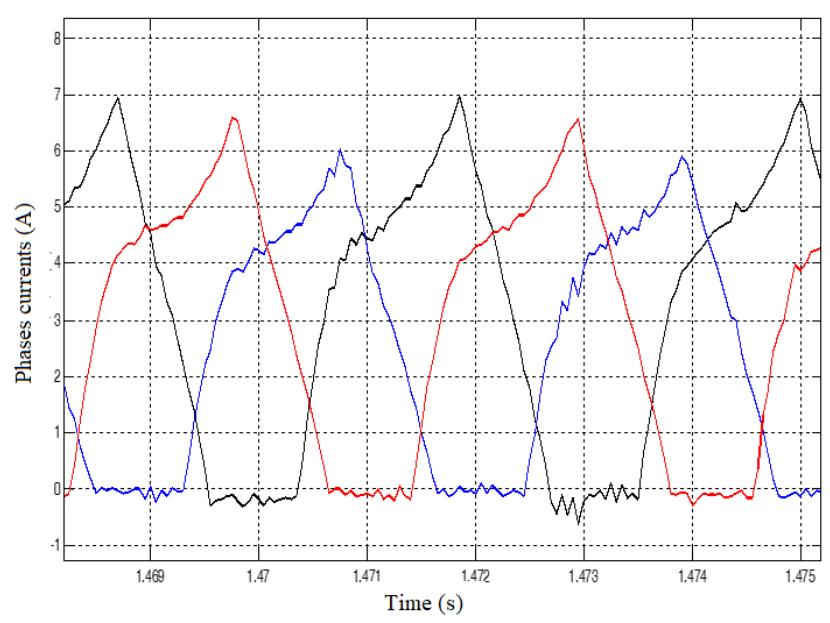

(b)

Fig. 13. Phases currents graphs. (a) The simulation results, (b) The experimental results.

It has been observed that the battery charging current had been decreased from 6.5 A to zero. The variations of the boost converter output current values obtained by the simulation and by experimental are displayed in Fig. 11 (a) and (b), respectively. It is seen that the ripple level in the experimental values was less than that in simulation values. The fault in the adjustment of PID controller coefficient causes higher ripples in output current of the boost converter. The variation graphics of the torque produced by the SRM and the loading torque needed by the pump versus time are shown in Fig. 12. The torque needed by the centrifugal pump is proportional to the square of the speed. When the rotor speed reaches its constant value, the loading torque remains constant. It is shown in Fig. 13 (a) and (b) that the experimental results of current values are very much alike to the simulation results. The water flow rate reduces at lower speeds of the pump. This is expected for high speed centrifugal pumps because flow rate becomes quite high at the speed values near the rated speed of the pump. The 
experimentally and simulation rotor speed graphs of SRM are shown in Fig. 14 (a) and (b).

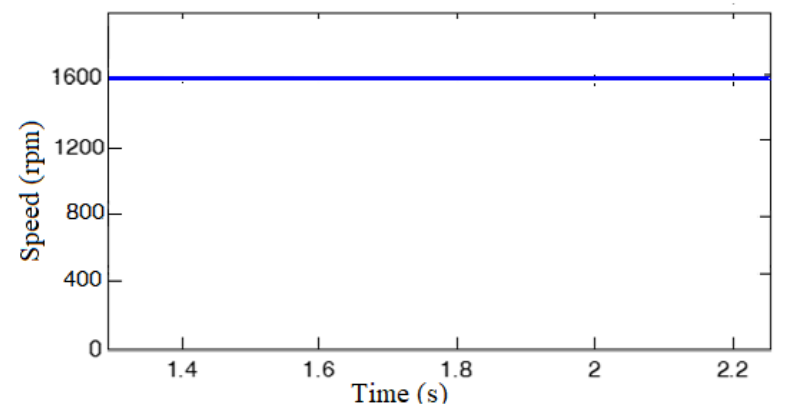

(a)

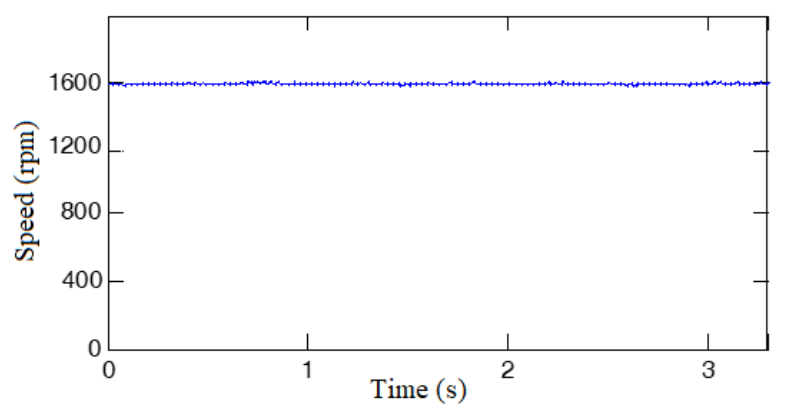

(b)

Fig. 14. Rotor speed graphs. (a) The simulation result, (b) The experimental result.

\section{CONCLUSIONS}

In this work, an SRM-driven water pumping system which works with solar power has been designed and implemented. Electric energy is generated and stored in batteries by utilizing of solar energy which is an infinitive source of energy. Low voltage level obtained from PVs has been increased to high voltage level required by SRM with DC-DC boost converter. It is utilized for turn on centrifugal pump by SRM due to its simple, robust structures stator and rotor without magnet and winding, low maintenance costs and high efficiency. The PV fed pumping system is simulated by using Matlab/Simulink software and simulation results are obtained. The experimental results are measured by hardware. Both experimental and simulation results are compared with each other. It is found that simulation results were very close to experimental results.

\section{REFERENCES}

[1] A. K. Mishra and B. Singh, "Solar photovoltaic array dependent dual output converter-based water pumping using switched reluctance motor drive," IEEE Trans. Ind. Appl., vol. 53, no. 6, pp. 5615-5623, Nov./Dec. 2017.

[2] A. Mudlapur, V. V. Ramana, R. V. Damodaran ,V. Balasubramanian, and S. Mishra, "Effect of partial shading on PV fed induction motor water pumping systems," IEEE Trans. Energy Convers., vol. 34, no. 1, pp. 530-539, Mar. 2019.

[3] Z. Omaç, "Fuzzy-logic-based robust speed control of switched reluctance motor for low and high speeds," Turk J Elec Eng \& Comp Sci, vol. 27, no. 1, pp. 316-329, 2019.
[4] Z. Omaç, M. Polat, E. Öksüztepe, M. Yıldırım, O. Yakut, H. Eren, M. Kaya, and H. Kürüm, "Design, analysis, and control of in-wheel switched reluctance motor for electric vehicles," Electr. Eng., vol. 100, no. 2, pp. 865-876, 2018.

[5] C. Gan, N. Jin, Q. Sun, W. Kong, Y. Hu, and L. M. Tolbert, "Multiport bidirectional SRM drives for solar-assisted hybrid electric bus powertrain with flexible driving and self-charging functions," IEEE Trans. Power Electron., vol. 33, no. 10, pp. 8231-8245, Oct. 2018.

[6] Y. Hu, C. Gan, W. Cao, Y. Fang, S. J. Finney, and J. Wu, "Solar PVpowered SRM drive for EVs with flexible energy control functions," IEEE Trans. Ind. Appl., vol. 52, no. 4, pp. 3357-3366, Jul./Aug. 2016.

[7] A. K. Mishra, B. Singh, "Design of solar-powered agriculture pump using new configuration of dual-output buck-boost converter," IET Renew. Power Gener., vol. 12 no. 14, pp. 1640-1650, 2018.

[8] V. Narayana, A. K. Mishra, and B. Singh, "Development of low-cost PV array-fed SRM drive-based water pumping system utilising CSC converter," IET Power Electron., vol. 10, no. 2, pp. 156-168, Feb. 2017.

[9] V. B. Koreboina, B. L. Narasimharaju, D. M. V. Kumar "Performance investigation of simplified PWM MPPT approach for direct PV-fed switched reluctance motor in water pumping system," IET Electr. Power Appl., pp. 1-11, Jul. 2017.

[10] A. K. Mishra, B. Singh, "Control of SRM drive for photovoltaic powered water pumping system," IET Electr. Power Appl., vol. 11, no. 6, pp. 1055-1066, 2017.

[11] B. Singh, A. K. Mishra, and R. Kumar, "Solar powered water pumping system employing switched reluctance motor drive," IEEE Trans. Ind. Appl., vol. 52, no. 5, pp. 3949-3957, Sep./Oct., 2016.

[12] B. C. Mecrow, J.W. Bennett, A. G. Jack, D. J. Atkinson, and A. J. Freeman, "Drive topologies for solar-powered aircraft," IEEE Trans. Ind. Electron., vol. 57, no. 1, pp. 457-464, Jan. 2010.

[13] R. Krishnan, Switched Reluctance Motor Drives: Modeling, Simulation, Analysis, Design and Applications. Boca Raton, FL, USA: CRC Press, Jun. 2001.

[14] Z. Omaç, H. Kürüm, A. H. Selçuk, "Digital current control of a switched reluctance motor," Int. J. Electr. and Power Eng., vol. 5, pp. 54-61, 2011.

[15] Z. Omaç, H. Kürüm, A. H. Selçuk, "Design, analysis and control of a switched reluctance motor having 18/12 poles," Firat U. J. Sci. Eng. vol. 19, pp. 339-346, 2007.

[16] M. A. Elgendy, B. Zahawi, D. J. Atkinson, "Comparison of directly connected and constant voltage controlled photovoltaic pumping systems," IEEE Trans. Sust. Energy, vol. 1, pp. 184-192, 2010.

[17] Z. Omaç, A. Özel, H. Kürüm, "Modeling a switched reluctance motorpump system directly fed from the photovoltaic battery using matlab simulink software," Nat. Conf. on Electr. Electronics Eng. (ELECO 2012), 29 Nov.-1 Dec., Bursa, Turkey, pp. 807-810, 2012.

\section{BIOGRAPHIES}

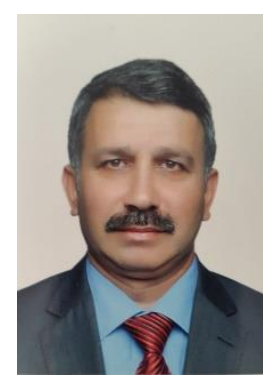

ZEKİ OMAÇ was born in Elazı̆ğ, Turkey, in 1968. He received the B.S., M.S., and Ph.D. degrees from Firat University, Elazığ, Turkey, in 1991, 19994, and 2006, respectively, all in electrical and electronics engineering.

Since 2009, he has been a Asst. Professor with the Department of Electrical and Electronics Engineering, Faculty of Engineering, Munzur University, Tunceli, Turkey. His research interests include design, analysis and control of switched reluctance motor, induction motor, permanent magnet motor, and pure electrical vehicles. 